\title{
Myocardial infarction marker levels are influenced by prothrombin and tumor necrosis factor- $\alpha$ gene polymorphisms in young patients
}

\author{
Loredana Vaccarino $^{\mathrm{a}, *}$, Silvana Vitale ${ }^{\mathrm{b}}$, Marco Caruso ${ }^{\mathrm{c}}$, Marisa Palmeri ${ }^{\mathrm{a}}$, Letizia Scola ${ }^{\mathrm{a}}$, Manuela Bova ${ }^{\mathrm{a}}$, \\ Calogero Caruso ${ }^{a}$, Maria Fatima Massenti ${ }^{b}$, Francesco Vitale $^{b}$, Salvatore Novo ${ }^{c}$, Domenico Lio ${ }^{a}$, \\ Giusi Irma Forte ${ }^{a}$
}

${ }^{a}$ Department of Biopathology and Medical and Forensic Biotechnology, University of Palermo, Italy

${ }^{\mathrm{b}}$ Department of Health Promotion Sciences, University of Palermo, Palermo, Italy

${ }^{\mathrm{c}}$ Department of Internal Medicine and Cardiovascular Diseases, University of Palermo, Palermo, Italy

\section{A R T I C L E I N F O}

\section{Article history}

Received 30 May 2012

Received in revised form 24 September 2012

Accepted 26 September 2012

Available online 22 October 2012

\section{Keywords:}

Acute myocardial infarction

Haematochemical parameters

SNPs

Pro-thrombin

Tumor necrosis factor- $\alpha$

\begin{abstract}
A B S T R A C T
Polymorphisms of genes encoding key factors for the control and activation of inflammatory response and coagulation cascade regulation may play a role in genetic susceptibility to acute myocardial infarction (AMI). This study sought to analyze the effect of TNF -308G/A and pro-thrombin (FII) 20210G/A polymorphisms on the laboratory parameters of young patients affected by AMI. Results indicated that TNF $-308 \mathrm{~A}$ positive genotype frequencies were increased in these patients and that a genetically determined higher production of TNF- $\alpha$ is associated in young subjects to a more severe cardiac damage as depicted by higher levels of troponin, Creatine kinase-MB Isoenzyme (mCK-MB) and a significant increased plasma fibrinogen levels. Similar and probably additive effects on might have a genetically determined increased production of pro-thrombin even if no significant differences in genotype frequencies of pro-thrombin (FII) 20210G/A polymorphisms were observed in this study. All together these results, indicating the relationship among genetically determined TNF $\alpha$ and FII production and increased levels of tissue damage markers of AMI, suggest that a complex genetic background, might be involved in susceptibility to AMI in young men influencing the extension and severity of the disease.
\end{abstract}

(c) 2012 Elsevier Ltd. All rights reserved.

\section{Introduction}

Acute myocardial infarction (AMI) the leading cause of mortality and morbidity in industrialized countries is a common outcome of coronary atherosclerosis. As other multifactorial disease, AMI probably involves many different gene variants that might interact to result in an additive or a synergistic co-effect. Young adults are a relatively small proportion of patients who experience AMI [1]. They have some distinct characteristics compared to older patients as young people are more likely to have normal coronary arteries

\footnotetext{
Abbreviations: AMI, acute myocardial infarction; aPTT, time (in seconds) of activated partial thromboplastin; AST, aspartate aminotransferase; CHD, coronary heart disease; CTnI, cardiac troponin I isoenzyme; FII, factor II (pro-thrombin); FV, factor V Leiden; HLA, human leukocyte antigen; IL-6, interleukin-6; IL-10, interleukin-10; INR, international normalized ratio; $\mathrm{MCK}-\mathrm{MB}$, creatine kinase-MB; PLTs, platelets; PT, prothrombin activity; SNPs, single nucleotide polymorphisms; TNF- $\alpha$, tumor necrosis factor- $\alpha$; UTR, upstream untranslated region.

* Corresponding author. Address: Department of Biopathology and Medical and Forensic Biotechnology, University of Palermo, Corso Tukory 211, 90134 Palermo, Italy. Fax: +39 0916555913 .

E-mail addresses: loredana.vaccarino@unipa.it, loredanavaccarino@libero.it (L. Vaccarino)
}

[2]. Although the exact pathogenetic mechanism of AMI in young patients remains unknown it has been proposed that thrombus formation due to atherosclerotic plaque rupture or erosion is, always, the main mechanism [3].

The importance of genetic factors seems to be particularly relevant in younger subjects, where it is assumed that the genetic background influences the susceptibility of these subjects to environmental risk factors for AMI identified in the general population. In particular a prominent role of genetic factors in the onset of this disease has been documented in twins and family based studies [4].

Recently a number of candidate genes and chromosomal loci have been identified to be associated with the susceptibility to myocardial infarction and a majority of these genes have been implicated in the processes of inflammation $[5,6]$. The single nucleotide polymorphisms (SNPs) present in the genes CD14 $(-159 \mathrm{C} / \mathrm{T})$, TNF $\alpha(-308 \mathrm{G} / \mathrm{A})$, IL-1a $(-889 \mathrm{C} / \mathrm{T})$, IL-6 $(-174 \mathrm{G} / \mathrm{C})$, PSMA6 $(-8 \mathrm{C} /$ $\mathrm{G}$ ), and PDE4D (SNP83 T/C, respectively), were found to be associated with increased risk of cardiovascular diseases in different populations [7-12]. In addition previous studies have shown that polymorphisms of genes encoding key factors for the control and 
activation of inflammatory response may play a role in genetic susceptibility to AMI in young men $[13,14]$.

In particular the pleiotropic pro-inflammatory cytokine tumor necrosis factor (TNF)-alpha, lying at the telomeric end of the class III region of the human leukocyte antigen (HLA) [15-18]. Play a central role in the inflammatory responses with multiple biologic activities.

Wilson and his colleagues [19] first reported the bi-allelic polymorphism within the $5^{\prime}$ genomic region of the TNF- $\alpha$ gene promoter at position -308 ( $-308 \mathrm{G} \rightarrow \mathrm{A}$; rs1800629). Carrying the $\mathrm{A}$ allele enhances transcriptional activity and is reported to be associated with higher levels of circulating TNF- $\alpha[20,21]$. Serum levels of TNF- $\alpha$ is elevated in coronary heart disease (CHD) patients and may modify the risk for developing coronary events since it affects endothelial cell hemostatic function [22] and in a recent metanalysis [23] it has been demonstrated that this polymorphism might be a risk factor for coronary heart disease.

Moreover congenital or acquired mutations located on genes coding for antithrombin III, protein $\mathrm{C}$, protein $\mathrm{S}$, factor $\mathrm{V}$ Leiden (FV) and prothrombin (FII), normally associated to the occurring of deep venous thrombosis, were also inconstantly found in patients with arterial thrombosis. Recent observations stressed the hypothesis that mutations of FV and FII may be risk factors for acute myocardial infarction [24-28].

The prothrombin gene is organized in 14 exons, separated by 13 introns with the $5^{\prime}$ upstream untranslated region (UTR) and the $3^{\prime}-$ UTR which may play regulatory roles in gene expression $[29,30]$. One genetic variation in the 3 '-UTR region of the prothrombin gene is the $\mathrm{G}$ to $\mathrm{A}$ transition at nucleotide position 20210, at or near the cleavage site of the mRNA precursor to which poly A is added. This was termed as the factor II G 20210A mutation. The prevalence of carriers of factor II 20210G/A substitution (rs1799963) in healthy Northern Europeans is 1.7\% whereas in Southern Europeans the prevalence is nearly double (3\%) [31].

In 1996, Poort et al. [29] reported that the 20210G/A single nucleotide polymorphism (SNP) is associated with an increased risk of venous thrombosis. Several studies confirmed this initial observation both in venous thrombosis and arterial disease [30,32].

In the present study, we analyze the frequencies of polymorphisms 20210G/A of FII and -308G/A of the promoter region of TNF- $\alpha$ in a group of Sicilian patients aged $<46$ years affected by AMI and evaluate the effect of these polymorphisms on the blood levels of myocardial tissue damage and clotting markers, to evaluate the possibility to use typing of these polymorphisms in association with selected haematochemical parameters in prognostic evaluation of these patients.

\section{Materials and methods}

\subsection{Subjects}

In this study, we analyzed two cohorts of men affected by acute myocardial infarction (AMI) and unrelated controls matched for age and sex. The cohort comprised 60 young male patients (age range 23-46 years) affected by acute myocardial infarction, consecutively admitted to the Cardiac Unit of Palermo University Hospital in the last year, and 130 healthy age and gender matched controls, all living in western Sicily. The diagnosis of acute myocardial infarction was based on standard laboratory (troponin I greater than decision limit, $3.0 \mathrm{ng} / \mathrm{mL}$ ) [33] findings, typical electrocardiographic changes and confirmed by echocardiography and coronary angiography. According to the Helsinki declaration and to local ethical committee recommendations for the observational studies, written informed consent for enrolling in the study and for personal data management was obtained from all the subjects. Blood samples from patients were collected $48 \mathrm{~h}$ from symptoms, transported and processed promptly according to preanalytical recommendations [34].

\subsection{Biochemical and hematological analyses}

Cardiac markers were examined by automatic analyzers in the fresh blood sample collected $48 \mathrm{~h}$ after myocardial infarction. The activity of aspartate aminotransferase (AST) and levels of CK-MB isoenzyme (CK-MB mass, $\mathrm{MCK}-\mathrm{MB}$ ) and Troponin I were quantified by routine chemical and immunochemichal clinical laboratory methods (Biochemical automatic analyzer: Modular $\mathrm{P}$ and $\mathrm{E}$, Roche, Basel, Switzerland); haemochromecytometric test was performed by analyzer Sismex 9500, coagulation tests: prothrombin activity (PT), time of activated partial thromboplastin (aPTT), fibrinogen Clauss by automatic analyzer Futura Advance.

\subsection{DNA genotyping}

Genomic DNA was isolated by a standard method using proteinase $\mathrm{K}$ digestion followed by a standard salting-out technique [16].

\subsubsection{Molecular analysis of alleles at the -308 nucleotide $(-308 G \rightarrow A)$ of TNF- $\alpha$ gene}

The $-308 \mathrm{G} / \mathrm{A}$ polymorphism (rs1800629) of TNF- $\alpha$ was identified using a modification of PCR-Restriction Fragment Length Polymorphism assay described by Galbraith and Pandey [35]. Briefly, $0.5 \mu \mathrm{M}$ of forward and reverse primers ( $5^{\prime}$ AGG CAA TAG GTT TTG AGG GCC AT $3^{\prime}$ and $5^{\prime}$ GGC GGG GAT TTG GAA AGT T $3^{\prime}$ ) were mixed to 5-10 ng of DNA template, with a final concentration of $0.2 \mathrm{U}$ Taq DNA polymerase (Perkin Elmer BioSystem, Rome, Italy), $200 \mu \mathrm{M}$ of each deoxynucleotide and $1 \mathrm{X}$ reaction buffer. PCR was performed for 35 cycles at $94{ }^{\circ} \mathrm{C}, 58^{\circ} \mathrm{C}$ and $72{ }^{\circ} \mathrm{C}$ for $35 \mathrm{~s}$, respectively. Restriction enzyme digestion with Ncol (M-Medical, Milan, Italy) of the PCR amplified product (159 bp) and subsequent electrophoresis on a $2-5 \%$ agarose gel discriminated between the two alleles; -308 A showed two fragments of $146 \mathrm{bp}$ and $13 \mathrm{bp}$, while $-308 \mathrm{G}$ was undigested and resulted in a single band of $159 \mathrm{bp}$. Heterozygous individuals were detected by the presence of all the three fragments.

\subsubsection{Molecular analysis of alleles at the 20210 nucleotide $(20210 \mathrm{G} \rightarrow$ A) of prothrombin (factor II) gene}

The identification of the alleles in the polymorphic site of Factor II was obtained by Real Time PCR using TaqMan Pre-Developed Assay Reagents for Allelic Discrimination essays optimized by Applied Biosystems on a 7300 Real Time PCR System as previously described [36]. Briefly, $10 \mathrm{ng}$ of DNA for each sample were used in a PCR reaction, containing $1 \mathrm{X}$ optimized master mix and $1 \mathrm{X}$ specific primers/probes mix assay, according to manufactory protocol in a final volume of $25 \mu \mathrm{l}$. Two identical probes, except for the central nucleotide that specifically recognizes the single nucleotide polymorphism (SNP) were used, each one labeled at the $5^{\prime}$ extremity with different dyes (for the wild-type allele the fluorochrome FAM, and the fluorochrome VIC for probe specific for minor allele) and at the $3^{\prime}$ extremity with a quencher dye, that in this case was the Minor Groove Binder (MGB) dye. Then, the amplification was performed in 7300 Real-Time ABI Prism PCR System (Applied Biosystems, USA), using a standard amplification protocol ( 1 cycle of $2^{\prime}$ at $50^{\circ} \mathrm{C} ; 1$ cycle of $10^{\prime}$ at $95^{\circ} \mathrm{C}$ and 40 cycles of $15^{\prime \prime}$ at $95^{\circ} \mathrm{C}$ plus $15^{\prime \prime}$ at $60^{\circ} \mathrm{C}$ ), and the results available in the report sheet of 7300 System SDS v1.3 Software. Finally, samples were graphically grouped in 3 genotypic clusters, easily recognizable in the Allelic Discrimination plot on the basis of the two probe's fluorescence intensity emissions, whereas the uncertain cases were also evalu- 
ated for the grow up of the fluorescence emission curve of each dye on the component's sheet.

\subsection{Statistical analysis}

The Hardy-Weinberg equilibrium was confirmed by Pearson's test (goodness of fit between the observed and expected genotype $(3 \times 2$ tables $)$ and allele $(2 \times 2$ tables $)$ frequencies $)$. Fisher's exact tests were performed to calculate significant different genotype or allelic distributions between patients with acute myocardial infarction and healthy controls. Odds ratio and 95\% of confidence intervals were calculated with Woolf's approximation to quantify the risk in carriers of minor allelic variants. Differences in quantitative and qualitative data were analyzed using formal statistical tests (ANOVA followed by $t$-Student test). Differences were considered significant when $p<0.05$.

\section{Results}

In previous studies we have demonstrated that proinflammatory gene variants determine an increased individual's risk for myocardial infarction [14]. Table 1 shows the analysis of genotypic frequencies of the single nucleotide polymorphisms of TNF $(-308 \mathrm{G} / \mathrm{A})$ an of the prothrombin (factor II, FII 20210G/A) among the 60 male patients and 130 healthy controls. Both patient' and control' genetic frequencies fit the Hardy-Weinberg equilibrium for both the two SNPs. We observed a significant increase of frequency of genotypes positive for the minor allele $(A)$ of $-308 \mathrm{G} / \mathrm{A}$ SNP $(p=0.0018)$, that are represented with a percentage of $36.7 \%$ among patients, against $14.6 \%$ among the healthy controls ( $p=0.0048$, odds ratio $4.00 ; 95 \%$ confidence interval: $1.51-10.56)$. In addition a not significant increase of the percentage of subject bearing the $20210 \mathrm{~A}$ allele of the factor II gene (8.3\% vs 6.9\%).

As well known AMI is diagnosed using some serum specific markers as Cardiac troponin I (CTnI) and Creatine kinase-MB Isoenzyme protein ( $\mathrm{mCK}-\mathrm{MB}$ ). Table 2 reports data on the effect of TNF -308 G/A and FII 20210G/A polymorphisms on the levels of these haematochemical markers, on the levels of Aspartate Transpeptidases (AST) measurement, nowadays considered obsolete for this purpose and leukocytes. Stratifying haematochemical data according the two SNP genotypes the higher levels of CTnI were observed in subject bearing the TNF- $\alpha-308 \mathrm{~A}$ or the FII 20210A alleles.

On the other hand subjects positive for $-308 \mathrm{~A}$ shows the higher levels of $\mathrm{mCK}-\mathrm{MB}$ whereas the FII 20210A ones shows the higher levels of leucocytes. The analysis of the effect of $-308 \mathrm{G} / \mathrm{A}$ TNF $\alpha$ and 20210G/A factor II genotypes on coagulation parameters, showed a significant increasing of plasma fibrinogen levels and of circulating platelets concentration in young men with acute myocardial infarction homozygous or heterozygous for $-308 \mathrm{~A}$ allele TNF $\alpha$ (Table 3). A similar pattern of fibrinogen concentration was observed in subjects bearing Factor II GA or AA genotypes.

\section{Discussion}

Signs of a systemic inflammatory response such as fever, leucocytosis and elevated acute phase reactants are frequently observed in patients with AMI and CHD. In patients with extensive myocardial infarction a pronounced inflammatory response may further complicate the clinical course [17]. After acute myocardial infarction, systemic inflammatory response is associated with the increases in plasma cytokines, such as TNF- $\alpha$, interleukin-6 (IL-6) and IL-10, in myocardium and blood. TNF- $\alpha$ as a pro-inflammatory cytokines and can cause severe damage to cardiomyocytes and suppress cardiac function [36].

In addition excessive thrombin generation has been described in individuals at high risk of fatal CHD [37]. It seems biologically plausible that the higher prothrombin levels related to the 20210A variant may also confer an increased risk of arterial disease.

Results reported in Table 1 confirm reports from previous researches $[13,14]$ on the role of TNF -308 A allele in AMI and suggest that this gene variant might be an AMI risk factor for young men but do not allow to confirm the association between FII 20210A allele and AMI. To date, actually, studies attempting to answer this question have yielded conflicting results. In some reports, being a carrier of the mutation was associated with an increased risk of acute myocardial infarction (AMI) [38,39]. Nevertheless, prospective studies failed to establish any association between the 20210A allele and AMI [40].

As reported in Table 1 the cumulative frequencies of genotypes positive for Prothrombin 20210A allele in our patients and control populations are almost doubled respect the published frequencies for the South Europe. These differences are probably due to the patient and control populations sampling (young men). So our subjects cannot be considered representative of the general population. On the other hand the North to South gradient in distribution of genotypes in Caucasians was established at $50^{\circ} \mathrm{N}$ latitude [8]. Sicily is at very South of this distribution so one could speculate that the frequency of Prothrombin 20210A allele might be further increased in our population. In all cases a different and larger population sample is necessary to determine Prothrombin 20210G/A genotype and allele frequencies in general Sicilian population.

Our data indicate that TNF -308G/A and FII 20210G/A polymorphisms impinge upon the levels of haematochemical markers associated to acute myocardial infarction. As well known the cardiac form of Cardiac troponin I (CTnI) levels are routinely measured for diagnosing acute myocardial infarction. Cardiac troponin measurements also provide information concerning prognosis and the effect of early intervention in patients with acute coronary syndromes. Similarly measurement of concentration of Creatine kinase-MB Isoenzyme protein (mCK-MB) represent an important marker of degree of myocardial damage immediately after AMI [41]. On the other hand Cardiac tissue necrosis induces an

Table 1

-308G/A TNF and 20210G/A FII genotype frequencies in 60 young patients affected by acute myocardial infarction (AMI) and 130 health sex and age matched controls.

\begin{tabular}{|c|c|c|c|c|c|c|c|c|}
\hline Genotypes & & AMI & $\%$ & Healthy controls & $\%$ & O.R. & 95\%C.I. & $p$ \\
\hline \multirow[t]{4}{*}{ TNF SNP $-308 \mathrm{G} / \mathrm{A}$} & GG & 38 & 63.4 & 111 & 85.4 & 0.29 & $0.14-0.62$ & 0.0018 \\
\hline & $A G$ & 20 & 33.3 & 17 & 13.1 & 3.43 & $1.58-7.45$ & 0.0026 \\
\hline & AA & 2 & 3.3 & 2 & 1.5 & 1.86 & $0.26-13.57$ & n.s \\
\hline & $\mathrm{AG} / \mathrm{AA}$ & 22 & 36.7 & 19 & 14.6 & 4.00 & $1.51-10.56$ & 0.0048 \\
\hline \multirow[t]{4}{*}{ Factor II SNP 20210G/A } & GG & 55 & 91.7 & 121 & 93.1 & 0.44 & $0.11-1.84$ & n.s. \\
\hline & AG & 4 & 6.6 & 7 & 5.4 & 1.26 & $0.35-4.46$ & n.s. \\
\hline & $\mathrm{AA}$ & 1 & 1.7 & 2 & 1.5 & 1.09 & $0.10-12.21$ & n.s. \\
\hline & AG/AA & 5 & 8.3 & 9 & 6.9 & 1.22 & $0.39-3.82$ & n.s. \\
\hline
\end{tabular}


Table 2

Evaluation of blood data (Mean \pm D.S.) of 60 young patients affected by acute myocardial infarction (AMI) according to tumor necrosis factor $\alpha$ (TNF $\alpha$ ) $-308 \mathrm{G} / \mathrm{A}$ and prothrombin (factor II) 20210G/A genotypes.

\begin{tabular}{llllll}
\hline Genotypes & CTnI & CK-MBm & AST & WBC & NEUT \\
\hline $\begin{array}{c}\text { TNF GG } \\
(38)\end{array}$ & $12.1 \pm 5.4$ & $23.5 \pm 9.2$ & $53.9 \pm 43.8$ & $9.2 \pm 1.6$ & $6.05 \pm 1.7$ \\
$\begin{array}{c}\text { TNF GA/AA } \\
(22)\end{array}$ & $20.8 \pm 7.6$ & $39.7 \pm 11.1$ & $61.7 \pm 30.8$ & $9.2 \pm 5.2$ & $6.9 \pm 5.1$ \\
$p$ & $<0.0001$ & $<0.0001$ & n.s. & n.s. & n.s. \\
$\begin{array}{l}\text { Factor II } \\
\text { GG (55) }\end{array}$ & $11.2 \pm 3.6$ & $26.5 \pm 8.7$ & $44.33 \pm 21.9$ & $8.7 \pm 4.8$ & $5.7 \pm 2.0$ \\
$\begin{array}{c}\text { Factor II } \\
\text { GA/AA } \\
\text { (5) }\end{array}$ & $19.9 \pm 6.7$ & $31.4 \pm 9.2$ & $75.9 \pm 41.1$ & $13.7 \pm 3.2$ & $9.33 \pm 4.4$ \\
$p \quad$ & & & & \\
\hline
\end{tabular}

Table 3

Evaluation of haematic coagulation marker profile (Mean \pm D.S.) of 60 young patients affected by acute myocardial infarction (AMI) according to tumor necrosis factor $\alpha$ (TNF $\alpha)-308 \mathrm{G} / \mathrm{A}$ and to prothrombin (factor II) 20210G/A genotypes.

\begin{tabular}{lllll}
\hline Genotypes & INR & APTT & $\begin{array}{l}\text { Fibrinogen } \mathrm{mg} / \\
\mathrm{dL}\end{array}$ & PLT $\times 10^{9} / \mathrm{L}$ \\
\hline TNF GG (38) & $1.01 \pm 0.07$ & $29.1 \pm 10.1$ & $364.5 \pm 41.1$ & $181.1 \pm 46.2$ \\
TNF GA/AA (22) & $1.03 \pm 0.16$ & $23.8 \pm 12.2$ & $418.15 \pm 113.0$ & $275.0 \pm 46.9$ \\
$p$ & n.s & n.s & 0.0110 & $<0.0001$ \\
Factor II GG (55) & $0.89 \pm 0.10$ & $29.1 \pm 15.6$ & $315.7 \pm 39.7$ & $295.0 \pm 56.3$ \\
$\begin{array}{l}\text { Factor II GA/AA } \\
\quad 1.00 \pm 0.23\end{array}$ & $29.0 \pm 25.3$ & $412.7 \pm 95.2$ & $250.0 \pm 61.1$ \\
$p$ & n.s. & n.s. & 0.0017 & n.s \\
\hline
\end{tabular}

increased inflammatory response mirrored by a not specific increase of circulating leucocytes due to neutrophil mobilization. Inflammatory response is an important feature of acute coronary syndromes and myocardial infarction. In AMI signs of inflammation are well known and elevated levels of acute phase reactants have been shown to be associated with a worse short- and longterm prognosis $[17,42]$. Our data strongly suggest that a genetically determined higher production of TNF- $\alpha$ is associated in young subjects to a more severe cardiac damage in AMI as depicted by higher levels of troponin and mCK-MB.

A similar and probably additive effect might have a genetically increased production of prothrombin. On the other hand considering the small number of patients ( 5 subjects) positive for the 20210A allele and the relative variability of results obtained in this small group of subjects the definition of weight of this genetic variant on haematochemichal marker necessitate further studies on larger group of subjects.

Fibrinogen is the major coagulation protein in blood by mass, the precursor of fibrin, and an important determinant of blood viscosity and platelet aggregation $[24,43]$. Our data indicate that subjects bearing proinflammatory or procoagulant genotypes have the high plasma fibrinogen. As well known starting from the seminal paper by Hashmi et al. [44], high fibrinogen levels are predictor of coronary artery lesions, more recently it has been reported that plasma fibrinogen level may predict critical coronary artery stenosis in young adults with myocardial infarction [45]. In this view our data seem to suggest that the typing of the studied SNP of TNF- $\alpha$ and of FII associated to plasma fibrinogen measurement might be an useful tool to the prognostic evaluation of IMA in young subjects.

\section{Conclusions}

All together the results of the present study, indicating the relationship among genetically determined TNF $\alpha$ and FII production and increased levels of tissue damage markers of AMI as well central molecules for clotting processes, suggest that a complex genetic background, might be involved in susceptibility to AMI in young men and in the extension and severity of the disease.

In conclusion our data might prompt an approach to defining individual risk profiles that can be applied to healthy subjects to predict intrinsic risk of AMI with different ages at onset. Such risk profiles, when better established in a larger cohort of patients, can be used to trigger further diagnostic procedures and early therapeutic interventions aimed at preventing or significantly delaying the clinical manifestations of cardiovascular disease.

\section{Acknowledgments}

This research was supported by grants from University of Palermo Research Financing Found 2007 to D.L. and L.S. L.V. is a PhD student and this work represents an implementation of her research project useful for her own final report.

\section{References}

[1] Doughty M, Mehta R, Bruckman D, et al. Acute myocardial infarction in the young. The University of Michigan experience. Am Heart J 2002;143:56-62.

[2] Zimmerman FH, Cameron A, Fisher LD, Ng G. Myocardial infarction in young adults: angiographic characterization, risk factors and prognosis (Coronary Artery Surgery Study Registry). J Am Coll Cardiol 1995;26:654-61.

[3] Williams MJ, Restieaux NJ, Low CJS. Myocardial infarction in young people with normal coronary arteries. Heart 1998;79:191-4.

[4] Zdravkovic S, Wienke A, Pedersen NL, de Faire U. Genetic susceptibility of myocardial infarction. Twin Res Hum Genet 2007;10:848-52.

[5] Hansson GK. Inflammation, atherosclerosis, and coronary artery disease. N Engl J Med 2005;352:1685-95.

[6] Ozaki K, Sato H, Iida A, et al. A functional SNP in PSMA6 confers risk of myocardial infarction in the Japanese population. Nat Genet 2006;38:921-5.

[7] Hubacek JA, Rothe G, Pit'ha J, et al. C(-260) $\rightarrow$ T polymorphism in the promoter of the CD14 monocyte receptor gene as a risk factor for myocardial infarction. Circulation 1999;99:3218-20.

[8] Georges JL, Loukaci V, Poirier O, et al. Interleukin-6 gene polymorphisms and susceptibility to myocardial infarction: the ECTIM study. Etude Cas-Temoin de l'Infarctus du Myocarde. J Mol Med 2001;79:300-5.

[9] Um JY, Moon KS, Lee KM, et al. Association of interleukin-1 alpha gene polymorphism with cerebral infarction. Brain Res Mol Brain Res 2003;115:50-4

[10] Bernard V, Pillois X, Dubus I, et al. The -308G/A tumor necrosis factor-alpha gene dimorphism: a risk factor for unstable angina. Clin Chem Lab Med 2003;41:511-6.

[11] Gretarsdottir S, Thorleifsson G, Reynisdottir ST, et al. The gene encoding phosphodiesterase 4D confers risk of ischemic stroke. Nat Genet 2003;35:131-8.

[12] Banerjee I, Gupta V, Ahmed T, Faizaan M, Agarwal P, Ganesh S. Inflammatory system gene polymorphism and the risk of stroke: a case-control study in an Indian population. Brain Res Bull 2008;75(1):158-65.

[13] Lio D, Candore G, Crivello A, et al. Opposite effects of interleukin 10 common gene polymorphisms in cardiovascular diseases and in successful ageing: genetic background of male centenarians is protective against coronary heart disease. J Med Genet 2004;41:790-4.

[14] Licastro F, Chiapelli M, Caldarera CM, Caruso C, Lio D, Corder E H. Acute myocardial infarction and proinflammatory. Gene Variants Ann NY Acad Sci 2007; 1119:227-42.

[15] Lio D, Candore G, Colombo A, et al. A genetically determined high setting of TNF-alpha influences immunologic parameters of HLA-B8, DR3 positive subjects: implications for autoimmunity. Hum Immunol 2001;62:705-13.

[16] Scola L, Crivello A, Marino V, et al. IL-10 and TNF-alpha polymorphisms in a sample of Sicilian patients affected by tuberculosis: implication for ageing and life span expectancy. Mech Ageing Dev 2003;124:569-72.

[17] Giacconi R, Caruso C, Malavolta M, et al. Pro-inflammatory genetic background and zinc status in old atherosclerotic subjects. Ageing Res Rev 2008;7:306-18.

[18] Forte GI, Scola L, Misiano G, et al. Relevance of gamma interferon, tumor necrosis factor alpha, and interleukin-10 gene polymorphisms to susceptibility to Mediterranean spotted fever. Clin Vaccine Immunol 2009;16:811-5.

[19] Wilson AG. Typing of tumor necrosis factor alleles. Methods Mol Biol 2003;210:297-304.

[20] Wilson AG, Symons JA, McDowell TL, McDevitt HO, Duff GW. Effects of a polymorphism in the human tumor necrosis factor alpha promoter on transcriptional activation. Proc Natl Acad Sci USA 1997;94:3195-9.

[21] Allen RD. Polymorphism of the human TNF-alpha promoter-random variation or functional diversity. Mol Immunol 1999;36:1017-27.

[22] Plutzky J. Inflammatory pathways in atherosclerosis and acute coronary syndromes. Am J Cardiol 2001;88:10-5. 
222

L. Vaccarino et al./ Cytokines 61 (2013) 218-222

[23] Chang HF, Xe SL, Wang JF, Chen YX, Wang Y, Huang TC. Tumor necrosis factoralpha $\mathrm{G}-308 \mathrm{~A}$ gene polymorphism and coronary heart disease susceptibility: an updated meta-analysis. Thromb Res 2011;127:400-5.

[24] Mannucci PM, Asselta R, Duna S, et al. The association of factor V Leiden with myocardial infarction is replicated in 1880 patients with premature disease. $J$ Thromb Haemost 2010;8:2116-21.

[25] Ye Z, Lu EH, Higgins JP, et al. Seven haemostatic gene polymorphisms in coronary disease: meta-analysis of 66,155 cases and 91,307 controls. Lancet 2006;367:651-8.

[26] Burzotta F, Leone AM, Paciaroni K, et al. G20210A prothrombin gene variant and clinical outcome in patients with a first acute coronary syndrome. Haematologic 2004;89:1134-8.

[27] Incalcaterra E, Hoffman E, Averna MR, Caimi G. Genetic risk factors in myocardial infarction at young age. Minerva Cardioangiol 2004;52: 287-312.

[28] Burzotta F, Paciaroni K, De Stefano V, et al. G20210A prothrombin gene polymorphism and coronary ischaemic syndromes: a phenotype-specific meta-analysis of 12,034 subjects. Heart 2004;90:82-6.

[29] Mort SR, Rosendaal FR, Reitsma PH, Bertina RM. A common genetic variation in the $3^{\prime}$-Untranslated region of the prothrombin gene is associated with elevated plasma prothrombin levels and an increase in venous thrombosis. Blood 1996;88:3698-703.

[30] Alhenc-Gelas M, Arnaud E, Nicaud V, et al. Venous thromboembolic disease and the prothrombin, methylene tetrahydrofolate reductase and factor $\mathrm{V}$ genes. Thromb Haemost 1999;81:506-10.

[31] Rosendaal FR, Doggen CJM, Zivelin A, et al. Geographic distribution of the 20210G to A prothrombin variant. Thromb Haemost 1998;79:706-8.

[32] Arruda VD, Bizzacchi JM, Goncalves MS, et al. Prevalence of the prothrombin gene variant (nt 20210A) in venous thrombosis and arterial disease. Thromb Haemost 1997;78:1430-3.

[33] Peetz D, Schweigert R, Jachmann N, Post F, Schinzel H, Lacker KJ. Method comparison of cardiac marker assays on PATHFAST, Stratus CS, AxSYM, Immulite 2000, triage, elecsys and cardiac reader. Chin Lab 2006;52:605-14.
[34] Lippi G, Guide GC. Risk management in the preanalytical phase of laboratory testing. Chin Chem Lab Med 2007;45:720-7.

[35] Galbraith GM, Pandey JP. Tumor necrosis factor alpha (TNF-alpha) gene polymorphism in alopecia reata. Hum Genet 1995;96:433-6.

[36] Vaccarino L, Forte GI, Palmeri M, et al. Role of prothrombotic polymorphisms in successful or unsuccessful aging. Biogerontology 2011;12:445-50.

[37] Miller GJ, Bauer KA, Barzegar S, et al. Increased activation of the hemostatic system in men at high risk of fatal coronary heart disease. Thromb Haemost 1996;75:767-71.

[38] Franco RF, Trip MD, ten Cate H, et al. The 20210GA mutation in the $3^{\prime}$ untranslated region of the prothrombin gene and the risk for arterial thrombotic disease. Br J Haematol 1999;104:50-4.

[39] Watzke HH, Schüttrumpf J, Graf S, et al. Increased prevalence of a polymorphism in the gene coding for human prothrombin in patients with coronary heart disease. Thromb Res 1997;87:521-6.

[40] Rider PM, Hennekens CH, Miletich JP. G20210A mutation in prothrombin gene and risk of myocardial infarction, stroke, and venous thrombosis in a large cohort of US men. Circulation 1999;99:999-1004.

[41] Cavallini C, Savonitto S, Violini R, et al. Italian 'Atherosclerosis, Thrombosis, and Vascular Biology' and 'Society for Invasive Cardiology-GISE' Investigators. Impact of the elevation of biochemical markers of myocardial damage on longterm mortality after percutaneous coronary intervention: results of the CK-MB and PCI study. Eur Heart J 2005;26:1494-8.

[42] Danish J, Collins R, Pets R, Lowe GDO. Haematocrit, viscosity, erythrocyte sedimentation rate: metaanalyses of prospective studies of coronary heart disease. Eur Heart J 2000;21:515-20.

[43] Lowe GDO. Fibrinogen and cardiovascular disease: historical introduction. Eur Heart J 1995;16(Suppl. A):2-5.

[44] Hashmi JA, Afroze N, Syed SA. Fibrinogen levels in patients suffering from acute myocardial infarction. J Atheroscler Res 1969;10:277-81.

[45] Tatli E, Ozcelik F, Aktoz M. Plasma fibrinogen level may predict critical coronary artery stenosis in young adults with myocardial infarction. Cardiol J 2009;16:317-20. 